\title{
Treatment of hypophosphatemia in the intensive care unit: a review
}

\author{
Daniël A Geerse ${ }^{1 *}$, Alexander J Bindels ${ }^{1}$, Michael A Kuiper ${ }^{2,3,4}$, Arnout N Roos ${ }^{1}$, Peter E Spronk ${ }^{3,4,5}$, \\ Marcus J Schultz $3,4,6$
}

\begin{abstract}
Introduction: Currently no evidence-based guideline exists for the approach to hypophosphatemia in critically ill patients.

Methods: We performed a narrative review of the medical literature to identify the incidence, symptoms, and treatment of hypophosphatemia in critically ill patients. Specifically, we searched for answers to the questions whether correction of hypophosphatemia is associated with improved outcome, and whether a certain treatment strategy is superior.

Results: Incidence: hypophosphatemia is frequently encountered in the intensive care unit; and critically ill patients are at increased risk for developing hypophosphatemia due to the presence of multiple causal factors. Symptoms: hypophosphatemia may lead to a multitude of symptoms, including cardiac and respiratory failure. Treatment: hypophosphatemia is generally corrected when it is symptomatic or severe. However, although multiple studies confirm the efficacy and safety of intravenous phosphate administration, it remains uncertain when and how to correct hypophosphatemia. Outcome: in some studies, hypophosphatemia was associated with higher mortality; a paucity of randomized controlled evidence exists for whether correction of hypophosphatemia improves the outcome in critically ill patients.

Conclusions: Additional studies addressing the current approach to hypophosphatemia in critically ill patients are required. Studies should focus on the association between hypophosphatemia and morbidity and/or mortality, as well as the effect of correction of this electrolyte disorder.
\end{abstract}

\section{Introduction}

Electrolyte disorders frequently develop in critically ill patients during course of stay in the intensive care unit (ICU). Therefore, ICU patients are routinely monitored for electrolyte disorders, and it is common practice to correct them. Hypophosphatemia is one of those frequently encountered electrolyte disorders, for which many causative factors are present in critically ill patients. It is uncertain when and how to correct hypophosphatemia, and whether correction affects outcome in critically ill patients.

We searched the literature on hypophosphatemia in ICU patients to identify the incidence, symptoms, and treatment of hypophosphatemia. We searched for answers to

\footnotetext{
* Correspondence: dgeerse@hotmail.com

'Department of Intensive Care Medicine, Catharina Hospital Eindhoven,

Michelangelolaan 2, Eindhoven, 5623 EJ, The Netherlands

Full list of author information is available at the end of the article
}

the following questions: (a) whether correction of hypophosphatemia is associated with improved outcome; and (b) whether a certain treatment strategy is superior.

\section{Materials and methods}

The Medline database was searched to identify articles from 1969 to 2010 containing the Medical Subjects Heading (MeSH) term "hypophosphatemia." We included clinical studies and experimental trials, as well as case reports. Results were limited to articles in the English language and to articles on humans. This search yielded 1,413 articles. The Cochrane Library was also searched for current trials on hypophosphatemia, which yielded no results. All articles were screened for relevance to critically ill patients; these articles were studied in detail. Notably, articles on chronic hypophosphatemia (for example, hereditary hypophosphatemic syndromes) were excluded. 


\section{Results}

Phosphate metabolism and causes of hypophosphatemia in critically ill patients

Phosphorus is an essential element for all living cells, with different functions (Table 1) [1]. The phosphate balance is a complex interplay between phosphate uptake and phosphate excretion (Figure 1). Normal values of the total serum phosphate level are 0.80 to $1.45 \mathrm{mmol} / \mathrm{L}$ (2.5 to $4.5 \mathrm{mg} / \mathrm{dl})$.

Hypophosphatemia can be caused by three different mechanisms [1,2]: decreased intestinal absorption, increased renal excretion, or internal redistribution of inorganic phosphate (Figure 1). In most patients with severe hypophosphatemia, both depletion of total body phosphorus stores and redistribution of phosphate to the intracellular space are found. Decreased intestinal absorption of phosphate rarely causes hypophosphatemia, as a low-phosphate diet increases renal reabsorption and enhances intestinal uptake of phosphate. Still, malnutrition, diarrhea, and nasogastric suction are common features in critically ill patients.

Redistribution across the cell membrane is the most common cause of hypophosphatemia in ICU patients and can be caused by multiple clinical conditions $[1,3]$ : respiratory alkalosis-induced increase of intracellular $\mathrm{pH}$ causes phosphate to enter the cell by stimulating glycolysis [4]; administration of glucose and insulin also stimulates carbohydrate metabolism, during which phosphate is transported into the cells along with glucose; high serum levels of catecholamines such as epinephrine and norepinephrine, whether endogenous or exogenous, cause a decrease in serum phosphate [5]; cellular uptake of phosphate is increased under certain specific conditions such as the hungry-bone syndrome, and diseases with rapid cell proliferation such as acute leukemia; renal excretion of phosphate is increased by metabolic acidosis, and by many drugs, including diuretics, glucocorticoids [6], aminoglycosides, antiretroviral drugs, and anticancer drugs.

Serum phosphate levels are inversely correlated to levels of the inflammatory cytokines interleukin- 6 and tumor necrosis factor- $\alpha$ [7]. The exact mechanism is unclear: renal phosphate excretion is very low in patients receiving interleukin therapy for cancer [8], suggesting that high interleukin levels cause internal redistribution of phosphate; hypophosphatemia may be caused by increased phosphate utilization by immune cells. Hypophosphatemia can be found in patients with severe infections, such as sepsis. Especially patients with Gram-negative bacteremia may develop hypophosphatemia [9]. Hypophosphatemia correlates to severity of illness and can even be used as a prognostic parameter in sepsis patients [10]. Infection with Legionella species is particularly associated with hypophosphatemia [11].

Hypophosphatemia often develops in the postoperative phase [12-15]. Multiple causal factors may be present, such as respiratory alkalosis, administration of insulin, and the use of diuretics. This is particularly true for major surgery, such as cardiac surgery and abdominal aortic surgery. The role of cardiopulmonary bypass is not clear. After major hepatic surgery, hypophosphatemia is extremely frequent. Reported mechanisms involve both shifts of phosphate into hepatocytes [16] and renal phosphate wasting [17]. Hypophosphatemia is reported to be more frequently encountered in trauma patients [18]. Renal phosphate handling is altered in trauma patients, resulting in inadequately increased urinary phosphate excretion. Hypophosphatemia is even more frequent in burn-wound victims, where phosphate is lost through the skin $[19,20]$. In patients with head trauma, induction of polyuresis may be an aggravating factor [21].

In patients with malnutrition, a so-called refeeding syndrome may develop when they receive (par-)enteral feeding, a syndrome characterized by multiple metabolic abnormalities including depletion of total body phosphorus stores and redistribution of phosphate to the intracellular compartment, which may result in severe hypophosphatemia [22].

Hypothermia induces polyuresis and is associated with hypophosphatemia as well [23]. The use of (continuous) renal replacement therapy may lead to hypophosphatemia when low-phosphate replacement solution and dialysate are used. Patients who require high-flux dialysis for

\section{Table 1 Functions of phosphate}

\begin{tabular}{ll}
\hline Form & Function \\
\hline Hydroxyapatite & Bone structure \\
Phospholipids & Structure of cell membranes \\
Adenosine triphosphate (ATP) and creatine phosphate & Energy storage and metabolism \\
Nucleic acids and nucleoproteins & Genetic translation \\
Phosphorylation of proteins & Key regulatory mechanism; activation of enzymes, cell-signaling cascade \\
2,3-Diphosphoglycerate & Modulates oxygen release by hemoglobin \\
Inorganic phosphate & Acid-base buffer \\
\hline
\end{tabular}




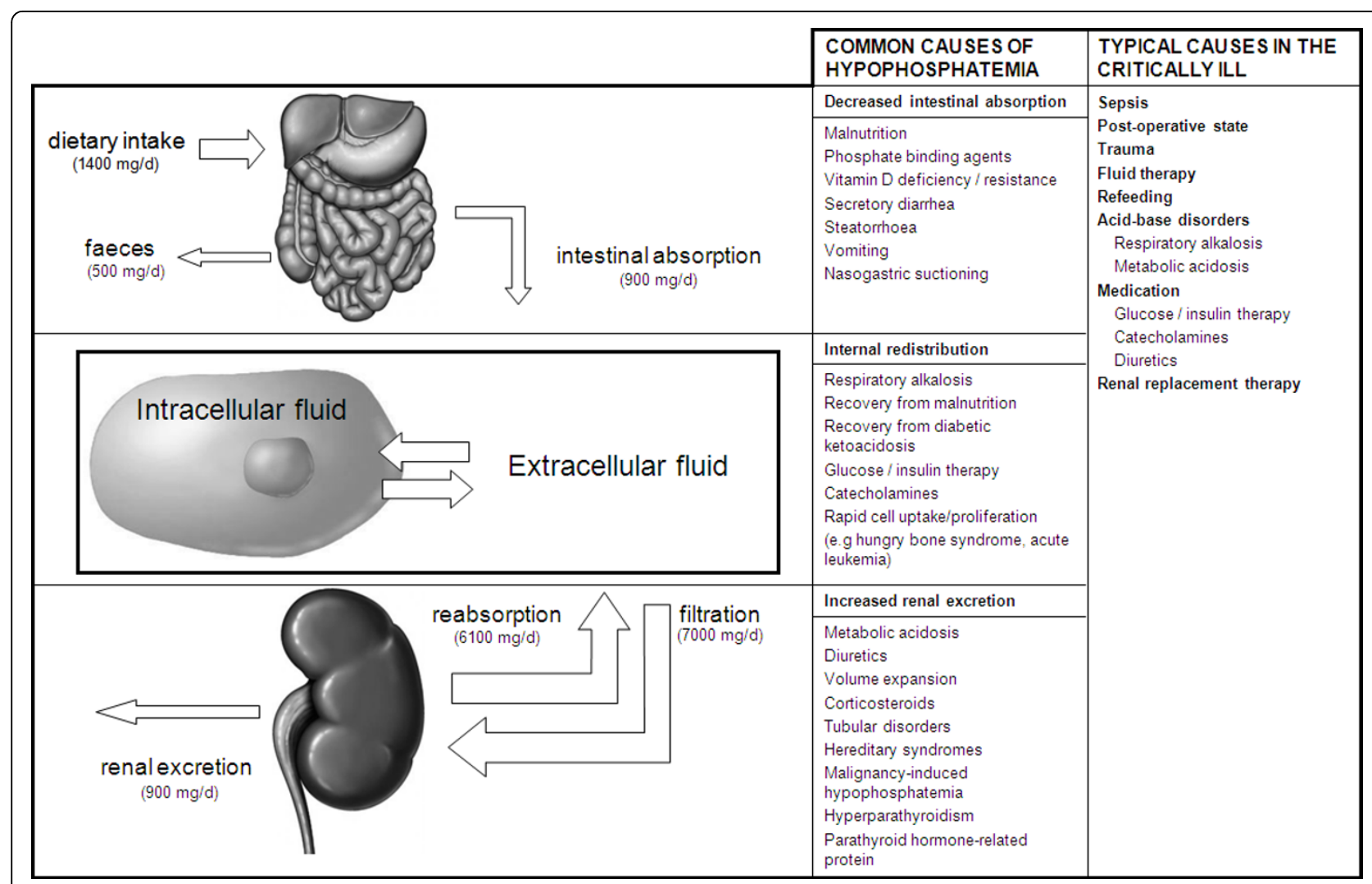

Figure 1 Phosphate metabolism and causes of hypophosphatemia.

intoxications are especially at risk. Addition of potassium phosphate to dialysate and replacement fluids safely prevents the development of hypophosphatemia [24].

Finally, patients with diabetic ketoacidosis commonly present with hypophosphatemia due to increased urinary phosphate excretion. Phosphate levels generally decrease further during treatment because of intracellular shifting along with glucose and potassium [25].

\section{Epidemiology of hypophosphatemia}

Table 2 summarizes the reported incidence and prevalence of hypophosphatemia in surgical and medical ICU patients $[7,12,14,15,17-19,21,26-30]$. Hypophosphatemia is usually categorized as moderate (serum phosphate level of 0.32 to $0.65 \mathrm{mmol} / \mathrm{L}$ ( 1 to $2 \mathrm{mg} / \mathrm{dl}$ ) or severe $(<0.32 \mathrm{mmol} / \mathrm{L}(<1 \mathrm{mg} / \mathrm{dl}))$. In the general hospital population, the prevalence of moderate hypophosphatemia ranges between 2.2 and $3.1 \%$ [31,32], and the prevalence of severe hypophosphatemia is reported to be 0.2 to $0.4 \%$ [32-34]. One study reports that $45 \%$ of all hospital hypophosphatemia cases occur in the ICU population [35]. Hypophosphatemia has a higher incidence in certain patient groups, such as patients with diabetic ketoacidosis, sepsis, and postoperative patients. Hypophosphatemia is found in as many as $34 \%$ of patients after elective cardiac surgery [12]. An extremely high incidence of hypophosphatemia is reported after major hepatic surgery, where almost all patients develop hypophosphatemia in the first postoperative week $[17,26]$. In this group, serum phosphate levels decrease to a nadir within approximately 2 days and recover in the following days. This early nadir is also described after cardiac surgery and in patients with diabetic ketoacidosis and the refeeding syndrome. Trauma patients have a higher incidence of hypophosphatemia, especially patients with burn wounds [19] and head trauma [21]. Although the use of renal replacement therapy leads to hypophosphatemia, no epidemiologic reports were found.

Correction of hypophosphatemia, when encountered, is not reported in epidemiologic studies and the spontaneous course of serum phosphate levels without treatment is generally not addressed.

\section{Symptoms of hypophosphatemia}

Serum phosphate levels do not accurately reflect total body phosphorus stores; hence the degree of hypophosphatemia does not always correlate to the presence of symptoms. Although most patients with hypophosphatemia do not develop symptoms, fatal complications have been described. A common mechanism in 
Table 2 Prevalence and/or incidence of hypophosphatemia

\begin{tabular}{|c|c|c|c|c|c|c|}
\hline Author [ref.] & Year & Population/disease & Number of patients & Definition of hypophosphatemia & Prevalence & Incidence \\
\hline \multicolumn{7}{|l|}{ Surgical ICU patients } \\
\hline \multirow[t]{2}{*}{ Goldstein et al. [15] } & 1985 & Thoracic surgery & 34 & $<0.80 \mathrm{mmol} / \mathrm{L}$ & - & $56 \%$ \\
\hline & & Cardiac surgery & 40 & $<0.80 \mathrm{mmol} / \mathrm{L}$ & - & $50 \%$ \\
\hline \multirow[t]{3}{*}{ Zazzo et al. [14] } & 1995 & Surgical ICU & 208 & $<0.80 \mathrm{mmol} / \mathrm{L}$ & - & $28.8 \%$ \\
\hline & & & & $\leq 0.50 \mathrm{mmol} / \mathrm{L}$ & - & $17.3 \%$ \\
\hline & & & & $\leq 0.20 \mathrm{mmol} / \mathrm{L}$ & - & $2.4 \%$ \\
\hline Buell et al. [26] & 1998 & Hepatic surgery & 35 & $<0.80 \mathrm{mmol} / \mathrm{L}$ & - & $67 \%$ \\
\hline Cohen et al. [12] & 2004 & Cardiac surgery & 566 & $<0.48 \mathrm{mmol} / \mathrm{L}$ & - & $34.3 \%$ \\
\hline Salem et al. [17] & 2005 & Hepatic surgery & 20 & $<0.70 \mathrm{mmol} / \mathrm{L}$ & - & $100 \%$ \\
\hline \multicolumn{7}{|l|}{ Medical ICU patients } \\
\hline \multirow[t]{2}{*}{ Daily et al. [18] } & 1990 & Trauma patients & 12 & $<0.80 \mathrm{mmol} / \mathrm{L}$ & - & $75 \%$ \\
\hline & & & & $<0.50 \mathrm{mmol} / \mathrm{L}$ & - & $56 \%$ \\
\hline Kruse et al. [27] & 1992 & General ICU patients & 418 & $<0.80 \mathrm{mmol} / \mathrm{L}$ & - & $28 \%$ \\
\hline \multirow[t]{2}{*}{ Marik et al. [28] } & 1996 & Refeeding after $>48$ h starvation & 62 & $<0.65 \mathrm{mmol} / \mathrm{L}$ & - & $34 \%$ \\
\hline & & & & $<0.32 \mathrm{mmol} / \mathrm{L}$ & - & $6 \%$ \\
\hline \multirow[t]{2}{*}{ Berger et al. [19] } & 1997 & Burn injuries & 16 & $<0.80 \mathrm{mmol} / \mathrm{L}$ & - & $100 \%$ \\
\hline & & & & $<0.30 \mathrm{mmol} / \mathrm{L}$ & - & $50 \%$ \\
\hline \multirow[t]{4}{*}{ Barak et al. [7] } & 1998 & Sepsis & 99 & $<0.80 \mathrm{mmol} / \mathrm{L}$ & $80 \%$ & - \\
\hline & & Infection without sepsis & 32 & $<0.80 \mathrm{mmol} / \mathrm{L}$ & $65 \%$ & - \\
\hline & & Sepsis, negative blood culture & 37 & $<0.80 \mathrm{mmol} / \mathrm{L}$ & $80 \%$ & - \\
\hline & & Sepsis, postive blood culture & 30 & $<0.80 \mathrm{mmol} / \mathrm{L}$ & $80 \%$ & - \\
\hline Polderman et al. [21] & 2000 & Head trauma & 18 & $<0.60 \mathrm{mmol} / \mathrm{L}$ & $61 \%$ & - \\
\hline Milionis et al. [29] & 2002 & Severe heart failure & 86 & $<0.77 \mathrm{mmol} / \mathrm{L}$ & $13 \%$ & - \\
\hline $\begin{array}{l}\text { Dominguez-Roldan } \\
\text { et al. [30] }\end{array}$ & 2005 & Brain-dead patients & 50 & $<0.80 \mathrm{mmol} / \mathrm{L}$ & - & $72 \%$ \\
\hline
\end{tabular}

hypophosphatemia-caused complications is impaired energy metabolism, leading to cellular dysfunction in multiple organ systems. Symptoms are summarized in Table 3.

\section{Respiratory effects}

Hypophosphatemia is associated with respiratory muscle dysfunction, potentially resulting in (acute) respiratory failure and weaning problems [36-38]. The mechanism is considered to be decreased availability of phosphatecontaining energy sources. Depletion of 2,3- diphosphoglycerate (2,3-DPG) shifts the oxygen dissociation curve to the left, decreasing oxygen delivery to peripheral tissue $[39,40]$. This might be especially relevant in patients with chronic pulmonary disease, as these patients may have higher 2,3-DPG levels to compensate for hypoxemia. In addition, hypophosphatemia has also been associated with decreased tissue oxygenation after correction for 2,3-DPG levels [41].

\section{Cardiovascular effects}

Hypophosphatemia can lead to myocardial dysfunction and arrhythmias. Phosphate depletion causes impaired energy metabolism in the myocardium, leading to decreased contractility $[42,43]$. Severe acute heart failure has been described in several case reports in the presence of severe hypophosphatemia. Hypophosphatemia after cardiac surgery was associated with higher requirements of inotropic support [12]. Correction of hypophosphatemia is associated with improved cardiac output [14]. Hypophosphatemia is a significant predictor of ventricular tachycardia after myocardial infarction [44] and a correlation with arrhythmias has been suggested in septic patients [45]. During correction of hypophosphatemia, phosphate may precipitate with calcium and cause hypocalcemia. It is important to keep in mind that hypocalcemia can negatively influence cardiac function as well.

\section{Other effects}

Hypophosphatemia can cause hematologic dysfunction [46-48], insulin resistance [49], and a number of neuromuscular symptoms (Table 3 ). Of the latter, rhabdomyolysis $[50,51]$ and central pontine myelinolysis $[52,53]$ are most severe. Besides hypophosphatemia, critically ill 
Table 3 Symptoms of hypophosphatemia

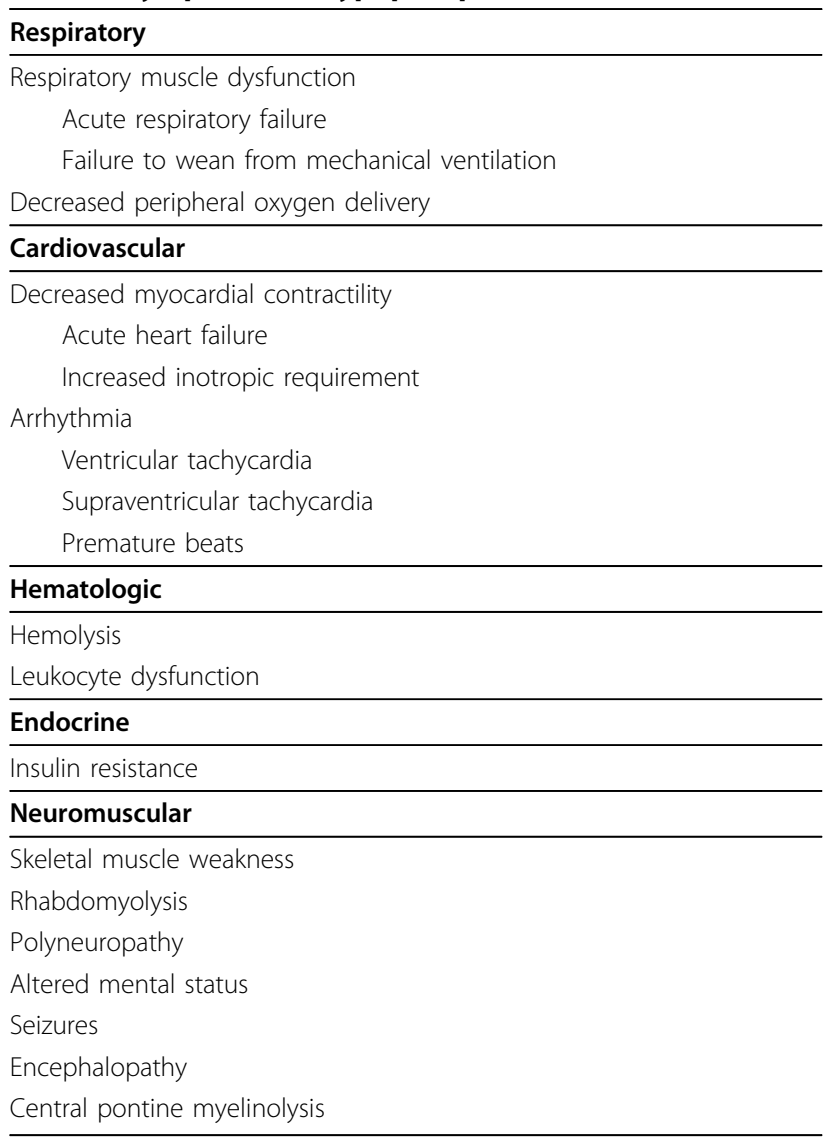

patients frequently have multiple factors putting them at risk for neurologic alterations, and causality is not well documented.

\section{Hypophosphatemia and mortality}

Multiple studies show an association between hypophosphatemia and increased mortality [10,12,14,35,54-59]. Severe hypophosphatemia has been reported to predict up to eightfold increased mortality rate in sepsis patients [10]. However, hypophosphatemia has not been associated with increased mortality after cardiac surgery [12] and in diabetic ketoacidosis [54]. It remains unclear whether hypophosphatemia actually contributes to mortality, or merely is a marker for severity of illness. Whether correction of hypophosphatemia reduces mortality is currently unknown.

\section{Correction of hypophosphatemia}

With the high prevalence of hypophosphatemia in critically ill patients, as well as their susceptibility to lifethreatening symptoms, frequent laboratory monitoring is recommended, especially in previously mentioned high-risk groups. It is generally recommended to correct hypophosphatemia in hypophosphatemic patients with associated symptoms $[2,60]$. However, no randomized controlled evidence indicates whether correction of hypophosphatemia in apparently asymptomatic patients leads to improved outcome. Taking this into account, the indication for - and recommended frequency of laboratory monitoring and treatment remains debatable.

Correction of hypophosphatemia is possible via oral or intravenous routes. Intravenous administration of phosphate is not without complications, though. Phosphate may precipitate with calcium. Large intravenous doses of phosphate may result in hyperphosphatemia, hypomagnesemia, hypocalcemia, and hypotension. It is therefore necessary to know when intravenous therapy is indicated, and how much and how fast phosphate should be supplied. Intravenous therapy is generally recommended in symptomatic hypophosphatemia and phosphate levels $<0.32 \mathrm{mmol} / \mathrm{L}$. Multiple studies have evaluated the efficacy and safety of intravenous phosphate repletion regimens (Table 4) [61-67]. These studies generally agree that aggressive phosphate supplementation is safe with phosphate doses up to $45 \mathrm{mmol}$ with infusion rates up to $20 \mathrm{mmol}$ per hour. Hyperkalemia is prevented by using sodium phosphate instead of potassium phosphate in patients with potassium levels $>4 \mathrm{mmol} / \mathrm{L}$.

Moderate hypophosphatemia can be treated with oral supplementation of phosphate. One should keep in mind that active vitamin $\mathrm{D}$ is required for intestinal absorption of phosphate. Typical oral supplementation amounts are three times the normal daily intake, with advised amounts of 2.5 to $3.5 \mathrm{~g}$ ( 80 to $110 \mathrm{mmol}$ ) per day, divided over two to three doses. Patients who receive feeding after a period of starvation are often phosphate depleted, so additional phosphate should be added to nutritional preparations. An additional preventive strategy is to build up the caloric intake slowly [22]. The total required amount of phosphate cannot be predicted by serum phosphate levels, as phosphate shifts between multiple body compartments.

Dipyridamole can decrease urinary phosphate loss [68]. Further research is needed to establish further the role of this drug in the treatment of hypophosphatemia in critically ill patients.

\section{Discussion}

Critically ill patients have a high prevalence of hypophosphatemia because of the presence of multiple causal factors. Hypophosphatemia may lead to a multitude of symptoms, but most often remains asymptomatic. Hypophosphatemia, however, is associated with increased mortality in important patient subgroups. It is important to investigate whether hypophosphatemia causes higher mortality in itself, or rather is associated with a higher severity of illness. 
Table 4 Intravenous treatment of hypophosphatemia

\begin{tabular}{|c|c|c|c|c|c|c|}
\hline Author [ref.] & Year & $\begin{array}{l}\text { Serum phosphate } \\
\text { (mmol/L) }\end{array}$ & Dose & Speed & Efficacy & Complications/safety \\
\hline \multirow[t]{3}{*}{$\begin{array}{l}\text { Brown et al. } \\
\text { [61] }\end{array}$} & 2006 & $0.73-0.96$ & $\begin{array}{l}0.32 \\
\mathrm{mmol} / \mathrm{kg}\end{array}$ & $7.5 \mathrm{mmol} / \mathrm{h}$ & No significant increase in iP & Considered safe \\
\hline & & $0.51-0.72$ & $\begin{array}{l}0.64 \\
\mathrm{mmol} / \mathrm{kg}\end{array}$ & $7.5 \mathrm{mmol} / \mathrm{h}$ & iP normalized in 59\% & Considered safe \\
\hline & & $<0.50$ & $1 \mathrm{mmol} / \mathrm{kg}$ & $7.5 \mathrm{mmol} / \mathrm{h}$ & iP normalized in $60 \%$ & Considered safe \\
\hline \multirow[t]{3}{*}{$\begin{array}{l}\text { Taylor et al. } \\
\text { [62] }\end{array}$} & 2004 & $0.55-0.70$ & $\begin{array}{l}0.2 \mathrm{mmol} / \\
\mathrm{kg}\end{array}$ & $\begin{array}{l}33 \mu \mathrm{mol} / \\
\mathrm{kg} / \mathrm{h}\end{array}$ & $\begin{array}{l}\text { iP normalized in } 76 \% \text { (all } \\
\text { patients) }\end{array}$ & Considered safe \\
\hline & & $0.32-0.55$ & $\begin{array}{l}0.4 \mathrm{mmol} / \\
\mathrm{kg}\end{array}$ & $\begin{array}{l}67 \mu \mathrm{mol} / \\
\mathrm{kg} / \mathrm{h}\end{array}$ & & Considered safe \\
\hline & & $<0.32$ & $\begin{array}{l}0.6 \mathrm{mmol} / \\
\mathrm{kg}\end{array}$ & $\begin{array}{l}100 \mu \mathrm{mol} / \\
\mathrm{kg} / \mathrm{h}\end{array}$ & & Considered safe \\
\hline \multirow[t]{4}{*}{$\begin{array}{l}\text { Charron et al. } \\
\text { [63] }\end{array}$} & 2003 & $0.40-0.65$ & $30 \mathrm{mmol}$ & $15 \mathrm{mmol} / \mathrm{h}$ & Equally effective & $\begin{array}{l}\text { Mild hyperphosphatemia and mild } \\
\text { hyperkalemia }\end{array}$ \\
\hline & & & $30 \mathrm{mmol}$ & $7.5 \mathrm{mmol} / \mathrm{h}$ & & \\
\hline & & $<0.40$ & $45 \mathrm{mmol}$ & $15 \mathrm{mmol} / \mathrm{h}$ & Equally effective & \\
\hline & & & $45 \mathrm{mmol}$ & $7.5 \mathrm{mmol} / \mathrm{h}$ & & \\
\hline \multirow{2}{*}{$\begin{array}{l}\text { Perreault et al. } \\
\text { [64] }\end{array}$} & 1997 & $0.40-0.80$ & $15 \mathrm{mmol}$ & $5 \mathrm{mmol} / \mathrm{h}$ & iP normalized in $81.5 \%$ & Considered safe \\
\hline & & $<0.40$ & $30 \mathrm{mmol}$ & $10 \mathrm{mmol} / \mathrm{h}$ & iP normalized in $30 \%$ & Considered safe \\
\hline $\begin{array}{l}\text { Rosen et al. } \\
{[65]}\end{array}$ & 1995 & $0.50-0.65$ & $15 \mathrm{mmol}$ & $7.5 \mathrm{mmol} / \mathrm{h}$ & iP normalized in $100 \%$ & Considered safe \\
\hline $\begin{array}{l}\text { Bollaert et al. } \\
\text { [66] }\end{array}$ & 1995 & $<0.65$ & $20 \mathrm{mmol}$ & $20 \mathrm{mmol} / \mathrm{h}$ & iP normalized in $80 \%$ & Considered safe Mild hypocalcemia \\
\hline Kruse et al. [67] & 1992 & $<0.80$ & $\begin{array}{l}20-40 \\
\mathrm{mmol}\end{array}$ & $20 \mathrm{mmol} / \mathrm{h}$ & $\begin{array}{l}\text { mean iP rose from } 0.65 \text { to } 1.0 \\
\mathrm{mmol} / \mathrm{L}\end{array}$ & considered safe Mild hypocalcemia \\
\hline
\end{tabular}

$\mathrm{iP}$, serum inorganic phosphate.

Because of the current paucity of evidence, serum phosphate levels are not routinely measured in all critically ill patients. The spontaneous course of serum phosphate is not well documented in the literature, so it is insufficiently clear whether an initially low phosphate level after surgery will return to normal spontaneously. Although multiple studies have evaluated the efficacy and safety of phosphate repletion regimens, the effect on mortality and morbidity is not well reported. Currently, no widely agreed-on guidelines exist concerning the approach to hypophosphatemia in critically ill patients, because evidence is lacking on when and how to treat hypophosphatemia.

A reasonable approach awaiting randomized controlled trial evidence would be to reserve intravenous correction of hypophosphatemia for patients with associated symptoms or phosphate levels $<0.32 \mathrm{mmol} / \mathrm{L}$. Doses of up to $40 \mathrm{mmol}$ of sodium phosphate, administered at a speed of up to $20 \mathrm{mmol}$ per hour, are proven to be safe. Additional studies are required, addressing the current approach to hypophosphatemia in critically ill patients, as well as the association of hypophosphatemia with morbidity and mortality, and the effect of treatment. Evidence-based guidelines are needed to guide critical care physicians in the diagnosis and treatment of hypophosphatemia.

\section{Conclusions}

Additional studies are required to address the current approach to hypophosphatemia in critically ill patients, as well as the association of hypophosphatemia with morbidity and mortality, and the effect of the correction of this electrolyte disorder.

\section{Key messages}

- Critically ill patients have a high prevalence of hypophosphatemia because of the presence of multiple causal factors.

- Hypophosphatemia may lead to a multitude of symptoms, including cardiac and respiratory failure, and is associated with higher mortality.

- Although multiple studies confirm the efficacy and safety of intravenous phosphate administration, it is unknown which treatment strategy is superior.

- Nevertheless, correction of hypophosphatemia has not been shown to improve outcome.

\section{Abbreviations}

2,3-DPG: 2,3-diphosphoglycerate; ATP: adenosine triphosphate; ICU: intensive care unit.

\section{Author details}

${ }^{1}$ Department of Intensive Care Medicine, Catharina Hospital Eindhoven, Michelangelolaan 2, Eindhoven, 5623 EJ, The Netherlands. ${ }^{2}$ Department of 
Intensive Care Medicine, Medical Centre Leeuwarden, PO Box 888, Leeuwarden, 8901 BR, The Netherlands. ${ }^{3}$ Department of Intensive Care Medicine, Academic Medical Center, University of Amsterdam, Meibergdreef 9, Amsterdam, 1105 AZ, The Netherlands. ${ }^{4}$ HERMES Critical Care Group, Meibergdreef 9, Amsterdam, Amsterdam, 1105 AZ, The Netherlands. ${ }^{5}$ Department of Intensive Care Medicine, Gelre Hospitals, location Lukas, PO Box 9014, Apeldoorn, 7300 DS, The Netherlands. 'Laboratory of Experimental Intensive Care and Anesthesiology (LEICA), Academic Medical Center, University of Amsterdam, Meibergdreef 9, Amsterdam, 1105 AZ, The Netherlands.

\section{Authors' contributions}

DAG searched the literature, interpreted the results, and drafted the manuscript. DAG, AJB, MAK, ANR, PES, and MJS participated in drafting and reviewing the manuscript. All authors approved the final version of the manuscript.

\section{Competing interests}

The authors declare that they have no competing interests.

Received: 28 October 2009 Revised: 2 June 2010

Accepted: 3 August 2010 Published: 3 August 2010

\section{References}

1. Gaasbeek A, Meinders AE: Hypophosphatemia: an update on its etiology and treatment. Am J Med 2005, 118:1094-1101.

2. Amanzadeh J, Reilly RF Jr: Hypophosphatemia: an evidence-based approach to its clinical consequences and management. Nat Clin Pract Nephrol 2006, 2:136-148.

3. Bugg NC, Jones JA: Hypophosphataemia: pathophysiology, effects and management on the intensive care unit. Anaesthesia 1998, 53:895-902.

4. Paleologos M, Stone E, Braude S: Persistent, progressive hypophosphataemia after voluntary hyperventilation. Clin Sci (Lond) 2000, 98:619-625.

5. Kjeldsen SE, Moan A, Petrin J, Weder AB, Julius S: Effects of increased arterial epinephrine on insulin, glucose and phosphate. Blood Press 1996, 5:27-31.

6. Murer $\mathrm{H}$, Hernando N, Forster I, Biber J: Proximal tubular phosphate reabsorption: molecular mechanisms. Physiol Rev 2000, 80:1373-1409.

7. Barak V, Schwartz A, Kalickman I, Nisman B, Gurman G, Shoenfeld Y: Prevalence of hypophosphatemia in sepsis and infection: the role of cytokines. Am J Med 1998, 104:40-47.

8. Webb DE, Austin HA, Belldegrun A, Vaughan $E$, Linehan WM, Rosenberg SA: Metabolic and renal effects of interleukin-2 immunotherapy for metastatic cancer. Clin Nephrol 1988, 30:141-145.

9. Riedler GF, Scheitlin WA: Hypophosphataemia in septicaemia: higher incidence in gram-negative than in gram-positive infections. Br Med J 1969, 1:753-756.

10. Shor R, Halabe A, Rishver S, Tilis Y, Matas Z, Fux A, Boaz M, Weinstein J: Severe hypophosphatemia in sepsis as a mortality predictor. Ann Clin Lab Sci 2006, 36:67-72.

11. Cunha BA: Hypophosphatemia: diagnostic significance in Legionnaires' disease. Am J Med 2006, 119:e5-6.

12. Cohen J, Kogan A, Sahar G, Lev S, Vidne B, Singer P: Hypophosphatemia following open heart surgery: incidence and consequences. Eur J Cardiothorac Surg 2004, 26:306-310.

13. Martinez MJ, Martinez MA, Montero M, Campelo E, Castro I, Inaraja MT: Hypophosphatemia in postoperative patients with total parenteral nutrition: influence of nutritional support teams. Nutr Hosp 2006, 21:657-660.

14. Zazzo JF, Troche G, Ruel P, Maintenant J: High incidence of hypophosphatemia in surgical intensive care patients: efficacy of phosphorus therapy on myocardial function. Intensive Care Med 1995, 21:826-831.

15. Goldstein J, Vincent JL, Leclerc JL, Vanderhoeft P, Kahn RJ: Hypophosphatemia after cardiothoracic surgery. Intensive Care Med 1985, 11:144-148.

16. George R, Shiu MH: Hypophosphatemia after major hepatic resection. Surgery 1992, 111:281-286.
17. Salem RR, Tray K: Hepatic resection-related hypophosphatemia is of renal origin as manifested by isolated hyperphosphaturia. Ann Surg 2005, 241:343-348.

18. Daily WH, Tonnesen AS, Allen SJ: Hypophosphatemia: incidence, etiology, and prevention in the trauma patient. Crit Care Med 1990, 18:1210-1214.

19. Berger MM, Rothen C, Cavadini C, Chiolero RL: Exudative mineral losses after serious burns: a clue to the alterations of magnesium and phosphate metabolism. Am J Clin Nutr 1997, 65:1473-1481.

20. Dickerson RN, Gervasio JM, Sherman JJ, Kudsk KA, Hickerson WL, Brown RO: A comparison of renal phosphorus regulation in thermally injured and multiple trauma patients receiving specialized nutrition support. JPEN $J$ Parenter Enteral Nutr 2001, 25:152-159.

21. Polderman KH, Bloemers FW, Peerdeman SM, Girbes AR: Hypomagnesemia and hypophosphatemia at admission in patients with severe head injury. Crit Care Med 2000, 28:2022-2025.

22. Marinella MA: Refeeding syndrome and hypophosphatemia. I Intensive Care Med 2005, 20:155-159.

23. Polderman KH, Peerdeman SM, Girbes AR: Hypophosphatemia and hypomagnesemia induced by cooling in patients with severe head injury. J Neurosurg 2001, 94:697-705.

24. Troyanov S, Geadah D, Ghannoum M, Cardinal J, Leblanc M: Phosphate addition to hemodiafiltration solutions during continuous renal replacement therapy. Intensive Care Med 2004, 30:1662-1665.

25. English P, Williams G: Hyperglycaemic crises and lactic acidosis in diabetes mellitus. Postgrad Med J 2004, 80:253-261.

26. Buell JF, Berger AC, Plotkin JS, Kuo PC, Johnson LB: The clinical implications of hypophosphatemia following major hepatic resection or cryosurgery. Arch Surg 1998, 133:757-761.

27. Kruse JA, Al-Douahji M, Carlson RW: Hypophosphatemia in critically ill patients: incidence and associations. Crit Care Med 1992, 20:S104.

28. Marik PE, Bedigian MK: Refeeding hypophosphatemia in critically ill patients in an intensive care unit: a prospective study. Arch Surg 1996, 131:1043-1047.

29. Milionis HJ, Rizos E, Liamis G, Nikas S, Siamopoulos KC, Elisaf MS: Acid-base and electrolyte disturbances in patients with hypercalcemia. South Med J 2002, 95:1280-1287.

30. Dominguez-Roldan JM, Jimenez-Gonzalez PI, Garcia-Alfaro C, HernandezHazanas F, Fernandez-Hinojosa E, Bellido-Sanchez R: Electrolytic disorders, hyperosmolar states, and lactic acidosis in brain-dead patients. Transplant Proc 2005, 37:1987-1989.

31. Betro MG, Pain RW: Hypophosphataemia and hyperphosphataemia in a hospital population. Br Med J 1972, 1:273-276.

32. Larsson L, Rebel K, Sorbo B: Severe hypophosphatemia: a hospital survey. Acta Med Scand 1983, 214:221-223.

33. King AL, Sica DA, Miller G, Pierpaoli S: Severe hypophosphatemia in a general hospital population. South Med J 1987, 80:831-835.

34. Camp MA, Allon M: Severe hypophosphatemia in hospitalized patients. Miner Electrolyte Metab 1990, 16:365-368.

35. Hoffmann M, Zemlin AE, Meyer WP, Erasmus RT: Hypophosphataemia at a large academic hospital in South Africa. J Clin Pathol 2008, 61:1104-1107.

36. Aubier $M$, Murciano $D$, Lecocguic $Y$, Viires $N$, Jacquens $Y$, Squara $P$, Pariente R: Effect of hypophosphatemia on diaphragmatic contractility in patients with acute respiratory failure. N Engl J Med 1985, 313:420-424.

37. Gravelyn TR, Brophy N, Siegert C, Peters-Golden M: Hypophosphatemiaassociated respiratory muscle weakness in a general inpatient population. Am J Med 1988, 84:870-876.

38. Agusti AG, Torres A, Estopa R, Agustividal A: Hypophosphatemia as a cause of failed weaning: the importance of metabolic factors. Crit Care Med 1984, 12:142-143.

39. Lichtman MA, Miller DR, Cohen J, Waterhouse C: Reduced red cell glycolysis, 2,3-diphosphoglycerate and adenosine triphosphate concentration, and increased hemoglobin-oxygen affinity caused by hypophosphatemia. Ann Intern Med 1971, 74:562-568.

40. Larsen VH, Waldau T, Gravesen H, Siggaard-Andersen O: Erythrocyte 2,3diphosphoglycerate depletion associated with hypophosphatemia detected by routine arterial blood gas analysis. Scand I Clin Lab Invest Suppl 1996, 224:83-87. 
41. Clerbaux T, Detry B, Reynaert M, Kreuzer F, Frans A: Reestimation of the effects of inorganic phosphates on the equilibrium between oxygen and hemoglobin. Intensive Care Med 1992, 18:222-225.

42. O'Connor LR, Wheeler WS, Bethune JE: Effect of hypophosphatemia on myocardial performance in man. N Engl J Med 1977, 297:901-903.

43. Brautbar N, Baczynski R, Carpenter C, Massry SG: Effects of phosphate depletion on the myocardium. Adv Exp Med Biol 1982, 151:199-207.

44. Ognibene A, Ciniglio R, Greifenstein A, Jarjoura D, Cugino A, Blend D, Whittier F: Ventricular tachycardia in acute myocardial infarction: the role of hypophosphatemia. South Med J 1994, 87:65-69.

45. Schwartz A, Gurman G, Cohen G, Gilutz H, Brill S, Schily M, Gurevitch B, Shoenfeld Y: Association between hypophosphatemia and cardiac arrhythmias in the early stages of sepsis. Eur J Intern Med 2002, 13:434.

46. Jacob HS, Amsden T: Acute hemolytic anemia with rigid red cells in hypophosphatemia. N Engl J Med 1971, 285:1446-1450.

47. Melvin JD, Watts RG: Severe hypophosphatemia: a rare cause of intravascular hemolysis. Am J Hematol 2002, 69:223-224.

48. Rasmussen A, Segel E, Hessov I, Borregaard N: Reduced function of neutrophils during routine postoperative glucose infusion. Acta Chir Scand 1988, 154:429-433.

49. Ravenscroft AJ, Valentine JM, Knappett PA: Severe hypophosphataemia and insulin resistance in diabetic ketoacidosis. Anaesthesia 1999, 54:198

50. Singhal PC, Kumar A, Desroches L, Gibbons N, Mattana J: Prevalence and predictors of rhabdomyolysis in patients with hypophosphatemia. Am J Med 1992, 92:458-464.

51. Knochel JP, Barcenas C, Cotton JR, Fuller TJ, Haller R, Carter NW: Hypophosphatemia and rhabdomyolysis. J Clin Invest 1978, 62:1240-1246.

52. Michell AW, Burn DJ, Reading PJ: Central pontine myelinolysis temporally related to hypophosphataemia. J Neurol Neurosurg Psychiatry 2003, 74:820.

53. Falcone N, Compagnoni A, Meschini C, Perrone C, Nappo A: Central pontine myelinolysis induced by hypophosphatemia following Wernicke's encephalopathy. Neuro/ Sci 2004, 24:407-410.

54. Wilson HK, Keuer SP, Lea AS, Boyd AE, Eknoyan G: Phosphate therapy in diabetic ketoacidosis. Arch Intern Med 1982, 142:517-520.

55. Fisher J, Magid N, Kallman C, Fanucchi M, Klein L, McCarthy D, Roberts I, Schulman G: Respiratory illness and hypophosphatemia. Chest 1983, 83:504-508.

56. Woodhead MA, Macfarlane JT: Legionnaires' disease: a review of 79 community acquired cases in Nottingham. Thorax 1986, 41:635-640.

57. Sankaran RT, Mattana J, Pollack S, Bhat P, Ahuja T, Patel A, Singhal PC: Laboratory abnormalities in patients with bacterial pneumonia. Chest 1997, 111:595-600

58. Vaidyanathan D, Venkatesan S, Ramadesikan VK: Serum phosphate in acute myocardial infarction. Indian J Physiol Pharmacol 2000, 44:225-228.

59. Chung PY, Sitrin MD, Te HS: Serum phosphorus levels predict clinical outcome in fulminant hepatic failure. Liver Transp/ 2003, 9:248-253.

60. Lentz RD, Brown DM, Kjellstrand CM: Treatment of severe hypophosphatemia. Ann Intern Med 1978, 89:941-944.

61. Brown KA, Dickerson RN, Morgan LM, Alexander KH, Minard G, Brown RO: A new graduated dosing regimen for phosphorus replacement in patients receiving nutrition support. JPEN J Parenter Enteral Nutr 2006, 30:209-214.

62. Taylor BE, Huey WY, Buchman TG, Boyle WA, Coopersmith CM: Treatment of hypophosphatemia using a protocol based on patient weight and serum phosphorus level in a surgical intensive care unit. J Am Coll Surg 2004, 198:198-204.

63. Charron T, Bernard F, Skrobik Y, Simoneau N, Gagnon N, Leblanc M: Intravenous phosphate in the intensive care unit: more aggressive repletion regimens for moderate and severe hypophosphatemia. Intensive Care Med 2003, 29:1273-1278.

64. Perreault MM, Ostrop NJ, Tierney MG: Efficacy and safety of intravenous phosphate replacement in critically ill patients. Ann Pharmacother 1997, 31:683-688.

65. Rosen GH, Boullata J, O'Rangers EA, Enow NB, Shin B: Intravenous phosphate repletion regimen for critically ill patients with moderate hypophosphatemia. Crit Care Med 1995, 23:1204-1210.

66. Bollaert PE, Levy B, Nace L, Laterre PF, Larcan A: Hemodynamic and metabolic effects of rapid correction of hypophosphatemia in patients with septic shock. Chest 1995, 107:1698-1701.

67. Kruse JA, Al-Douahji M, Carlson RW: Rapid intravenous phosphate replacement in critically ill patients. Crit Care Med 1992, 20:5104.
68. Prie D, Blanchet FB, Essig M, Jourdain JP, Friedlander G: Dipyridamole decreases renal phosphate leak and augments serum phosphorus in patients with low renal phosphate threshold. J Am Soc Nephrol 1998, 9:1264-1269.

doi:10.1186/cc9215

Cite this article as: Geerse et al:: Treatment of hypophosphatemia in the intensive care unit: a review. Critical Care 2010 14:R147.

\section{Submit your next manuscript to BioMed Central and take full advantage of:}

- Convenient online submission

- Thorough peer review

- No space constraints or color figure charges

- Immediate publication on acceptance

- Inclusion in PubMed, CAS, Scopus and Google Scholar

- Research which is freely available for redistribution

Submit your manuscript at www.biomedcentral.com/submit
C Biomed Central 